\title{
AN EGGSHELL HYDROXYAPATITE - GRAPHENE OXIDE NANOCOMPOSITE FOR THE REMOVAL OF HEAVY METALS FROM WASTE WATER
}

\author{
Osama H. Radwan ${ }^{(1)}$; Mohamed A. Ahmed ${ }^{(2)}$ \\ Ashraf A. Mohamed ${ }^{(2)}$ \\ 1) Chemical warfare central laboratories, Egyptian Armed Forces 2) Faculty \\ of Science, Ain Shams University
}

\begin{abstract}
Heavy metal pollution is a serious environmental problem that can be remediated by various adsorbents. So, a new hydroxyapatite / graphene oxide nanocomposite $(\mathrm{HAp} / \mathrm{GO})$ material was synthesized from waste eggshell as a green and eco-friendly adsorbent for the effective removal of heavy metals (e.g., $\mathrm{Cd}, \mathrm{Pb}, \mathrm{Cr}, \mathrm{Ni}, \mathrm{Co}$ ) from wastewaters. Nano-structured HAp was synthesized by calcination of the waste eggshell followed by hydrothermal treatment in the presence of phosphate solution. However, GO was synthesized using the Hummar's method (Guerrero-Contreras and CaballeroBriones, 2015). The HAp/GO nanocomposite was synthesized from the HAp and GO precursors by ultrasonic treatment. The morphology, composition, crystal structure, functionality and stability of the synthesized sorbent were evaluated using Fourier transform infrared spectrophotometry (FTIR), highresolution transmission electron microscopy (HR-TEM), scanning electron microscope (SEM), energy dispersive X-ray (EDX), X-ray diffraction (XRD), Raman spectrometry and $\mathrm{N}_{2}$-BET (Barrett-Emmett-Teller) surface area measurement techniques. The equilibrium concentrations of heavy metals were measured using Inductively Coupled Plasma-Mass Spectrometry (ICPMS). The effect of the initial concentration of heavy metals, the dosage of $\mathrm{HAp} / \mathrm{GO}$, temperature effect and the solution $\mathrm{pH}$ on the adsorption capacity was investigated. The synthesized HAp/GO was adopted to achieve superior
\end{abstract}


simultaneous removal efficiencies $(\geq 90 \%)$ for $(\mathrm{Cd}, \mathrm{Pb}, \mathrm{Cr}, \mathrm{Ni}, \mathrm{Co})$ metal ions.

Keywords: Adsorption, Heavy metals, Waste eggshell hydroxyapatite/ graphene oxide nanocomposite.

\section{INTRODUCTION}

Eggshells are waste materials from hatcheries, households and fast food industries and can be obtained readily in huge amounts, especially in areas of germination labs and poultry farms (Laca et al., 2017). eggshell Waste disposal leads to environmental contamination problems associated with the disposal of eggshells, including costs, availability of disposal sites and odor, (Chung et al., 2019). However, waste disposal can be converted into saleable products such as fertilizers, artworks, human and animal nutrition and building materials for health and for water treatment.

Another environmental problem which affect all living organisms is the contamination of water with heavy metal that emerge from various industry such as electroplating, metal finishing, metallurgy and chemical manufacturing which make water unsuitable for use in various purposes (Ali et al., 2019).

The egg shell composition is around 98.2, 0.9, 0.9 per cent Calcium carbonate, Magnesium and Phosphorous (phosphate)respectively (Hincke et al., 2012). The content of calcium carbonate in eggshell make a possibility to convert and recycling eggshell to another material such as hydroxyapatite powder $\left(\mathrm{Ca}_{10}\left(\mathrm{PO}_{4}\right)_{6}(\mathrm{OH})_{2}\right.$, HA) which play an important role in heavy metal removal from waste water (Lee et al., 2013). Although the composition of 2 
eggshell is suitable for various industrial application, however, the surface area and the functionality are very low that limit its wide application (Rahmani-Sani et al., 2020).

In recent years, graphene (the thinnest material in universe and the twodimensional carbon sheet with one atom thickness) nanocomposites and hybrids have attracted increasing attention for real applications in energy, electrochemical, catalytic and environmental aspects (Chang and $\mathrm{Wu}, 2013$ ).

The diversity in graphene's applications was inspired from the unique properties as the high theoretical surface area $\left(2630 \mathrm{~m}^{2} / \mathrm{g}\right)$, enhanced mobility $\left(200,000 \mathrm{~cm}^{2} \mathrm{~V}^{-1} \mathrm{~s}^{-1}\right.$ at carrier density of $\left.\sim 1012 \mathrm{~cm}^{-2}\right)$, improved electrical conductivity at room temperature $\left(106 \mathrm{~s} \mathrm{~cm}^{-1}\right)$, high mechanical properties and excellent thermal conductivity $\left(\sim 5000 \mathrm{~W} \mathrm{~m}^{-1} \mathrm{~K}^{-1}\right)$. Environmentally, graphene composites have shown excellent activity for the adsorption/removal of metals ions from wastewater (Vilela et al., 2016).

Aim of this study to compile the virtues of HAp and graphene (HAp/GO) nanocomposite for the removal of heavy metals $(\mathrm{Cd}, \mathrm{Pb}, \mathrm{Cr}, \mathrm{Ni}, \mathrm{Co})$ in wastewater treatments. 


\section{MATERIALS AND METHODS}

All chemicals employed in this investigation including graphite powder (NICE), sulphuric acid $\left(\mathrm{H}_{2} \mathrm{SO}_{4}, 95-97 \%\right.$, Merck), sodium nitrate $\left(\mathrm{NaNO}_{3}\right.$, 99.5\%, Merck), potassium permanganate $\left(\mathrm{KMnO}_{4}, 99.0 \%\right.$, Merck), hydrogen peroxide $\left(\mathrm{H}_{2} \mathrm{O}_{2}, 35 \%\right.$, Merck), ammonium hydroxide $\left(\mathrm{NH}_{4} \mathrm{OH}\right.$, SigmaAldrich), phosphoric acid $\left(\mathrm{H}_{3} \mathrm{PO}_{4}\right.$, Sigma-Aldrich), hydrochloric acid $(\mathrm{HCl}$, $38 \%$, Sigma-Aldrich), and ( $\mathrm{Cd}, \mathrm{Pb}, \mathrm{Cr}, \mathrm{Ni}, \mathrm{Co})$ metals standard solution (accustandard).

\section{Synthesis of hydroxyapatite powder $\left(\mathrm{Ca}_{10}\left(\mathrm{PO}_{4}\right)_{6}(\mathrm{OH})_{2}\right.$, $\left.\mathrm{HA}\right)$ from}

waste eggshell: Eggshells were obtained, and manually handled their surfaces. They were then put in an oven for a thermal treatment of two stages. The first stage consisted of heating the eggshells up to $450^{\circ} \mathrm{C}$ at a heating rate of $5{ }^{\circ} \mathrm{C} / \mathrm{min}$ for $2 \mathrm{~h}$; any organic residues are supposed to be eliminated at this temperature. The second stage also consisted of heating the samples for $2 \mathrm{~h}$ to $700{ }^{\circ} \mathrm{C}$ but with a heating rate of $0.5^{\circ} \mathrm{C} / \mathrm{min}$. At this temperature, according to the following equation, the eggshells turn into calcium oxide by releasing carbon dioxide $\mathrm{CO}_{2}$ :

$$
\mathrm{CaCO}_{3} \rightarrow \mathrm{CO}_{2}+\mathrm{CaO}(1)
$$

In a phosphate solution the $\mathrm{CaO}$ thus collected from the eggshells was then converted into HAp. The concentrations of the reactants were calculated simply by the fact that $5.54 \mathrm{~g}$ of $\mathrm{CaO}$ corresponds to $1 \mathrm{~g}$ of. $\mathrm{Ca}_{3}\left(\mathrm{PO}_{4}\right)_{2}$ and also by the $\mathrm{Ca} / \mathrm{P}$ ratio for HAp equal to 1.67 . In a jar designed to replicate a humid atmosphere, the $\mathrm{CaO}$ from eggshells was then applied to the solution.. 
Subsequently, the container was sealed and heated to $1050^{\circ} \mathrm{C}$ for $3 \mathrm{~h}$ at the heating rate of $10^{\circ} \mathrm{C} / \mathrm{min}$. The expected reaction is:

$$
\mathrm{Ca}_{3}\left(\mathrm{PO}_{4}\right)_{2}+\mathrm{CaO}+\mathrm{H}_{2} \mathrm{O} \rightarrow \mathrm{Ca}_{10}\left(\mathrm{PO}_{4}\right)(\mathrm{OH})_{2}(2)
$$

Once the reaction was completed, the solution was filtered and the resulting material dried overnight at $80^{\circ} \mathrm{C}$ in an oven (Hui et al., 2010).

2. Synthesis of Graphene Oxide (GO): GO was prepared according to the modified Hummer method (Zaaba et al., 2017). In detail, $5 \mathrm{~g}$ of graphite and $2.5 \mathrm{~g}$ of $\mathrm{NaNO}_{3}$ were mixed with $108 \mathrm{~mL} \mathrm{H}_{2} \mathrm{SO}_{4}$ and stirred in an ice bath for $10 \mathrm{~min}$.

Next, add slowly $15 \mathrm{~g}$ of $\mathrm{KMnO}_{4}$ and keep the temperature remained below $5^{\circ} \mathrm{C}$ by placed the mixture an ice bath for 2 hours and stirred for 60 minutes before being stirred again for 60 minutes in a $4^{\circ} \mathrm{C}$ water bath. The mixture temperature was set for $60 \mathrm{~min}$ to a steady $9^{\circ} \mathrm{C}$ when continuously adding water. Deionized water was further added so that the volume of the suspension was $400 \mathrm{~mL} .15 \mathrm{~mL}$ of $\mathrm{H}_{2} \mathrm{O}_{2}$ was added after $5 \mathrm{~min}$. The reaction product was centrifuged and washed with deionized water and $5 \% \mathrm{HCl}$ solution repeatedly. Finally, the product was dried at $40^{\circ} \mathrm{C}$

3. Graphene-hydroxyapatite nanocomposite (HAp) synthesis: Graphenebased powders were first dissolved and exfoliated by ultrasonic dispersion in DI water to achieve a uniform solution; then hydroxyapatite was applied to graphene-based solutions by stirring for the desired time; subsequently, the $\mathrm{pH}$ of the suspension was changed to 9-10 using 30 percent ammonium hydroxide by adding drop wise to the mixture. 
During this process, the oxygen-containing functional groups on GO surfaces behave as receptor sites for $\mathrm{Ca}^{2+}$ through electrostatic interactions (Hassan et al., 2018); the distribution and the microstructures of HAp on graphene are mainly influenced by the amounts and types of the oxygenous groups on the graphene-based templates, the concentration of the reagents $\left(\mathrm{Ca}^{2+}\right.$ and $\left.\mathrm{HPO}_{4}{ }^{2-}\right)$, solution and $\mathrm{pH}$ values and so on.Composite, prepared by this method is expected to increase the interfacial bonding strength between graphene and HAp, thereby enabling the transfer of stress from the matrix to the nanofillers based on graphenes. This simple approach is economical, and can be mass-produced industrially..

\section{Graphene-hydroxyapatite nanocomposite (HAp) characterization:}

Morphological images of the samples were characterized by using the high resolution transmission electron microscopy (HR-TEM, GEOL F200) could inspect the surface topography and bulk composition of the HAp/GO nanocomposite revealing interesting information about the material's crystallinity. In this investigation, particles were suspended onto $200 \mathrm{mish}$ $\mathrm{Cu}$ grids coated with a carbon film. The bright field and diffraction pattern imaging techniques were employed at $200 \mathrm{kV}$ using LaB6 electron source gun.

The PHILIPS Scanning Electron Microscope (SEM) operating in beam mode with a secondary electron detector. For SEM samples preparation 0.4 $\mathrm{mg} / \mathrm{ml}$ solutions in water were used for HAp , GO and HAp/GOcomposites, deposited onto a silicon oxidesubstrate $\left(\mathrm{SiO}_{2}\right.$, oxide thickness $\left.270 \mathrm{~nm}\right)$. The 6 
HAp and GO deposition (about $200 \mu \mathrm{L}$ ) was carried out by Spin-Coating which makes it possible to obtain thin and homogeneous films. HAp/GO composites were instead deposited by Drop-Casting. The samples were transferred to a conductive adhesive carbon tape held on a SEM sample holder for analysis. An Energy Dispersive X-ray analyzer (EDX) was used for the analysis of the elemental composition. Elemental spectra were taken during SEM observations which allow qualitative detection and localization of elements present in the composites.

A PANALYTICAL X'Pert Pro analyzer was used to study XRD patterns of the powder samples. The XRD analyzer was equipped with a $\mathrm{Cu} \mathrm{Ka}$ radiation source $(\lambda=1.5406 \AA)$. The diffraction angles $2 \theta$ were set between 3 and 70 until a fine powder was obtained.

The functional groups of samples were analyzed with JASCO Fourier Transform Infrared (FTIR) spectroscopy measurements. FTIR spectra were performed at room temperature in the wavelength range $4,000-400 \mathrm{~cm}$, with the accumulation of 16 repeated scans. To prepare the samples for FTIR analysis, the powder was completely dried in an oven for at least $24 \mathrm{hr}$ at $40^{\circ} \mathrm{C}$ and then mixed with potassium bromide $(\mathrm{KBr})$ anhydrous to make the pellets.

Raman spectra were collected using a BRUKER system $(\lambda=633 \mathrm{~nm}, 1$ $\mu \mathrm{m}$ spatial resolution, and $\approx 2 \mathrm{~cm}$ spectral resolution) equipped with a SENTERRA optical microscope (20x MPLAN objective). The analyses were performed on samples of a $1 \mathrm{mg} / \mathrm{mL}$ solution by drop-casting on a Si water. 
HAp/GOanalyzes were performed by depositing by Drop-Casting about 100 $\mu \mathrm{L}$ of each sample on $270 \mathrm{~nm}$ thick $\mathrm{SiO}_{2}$ substrates.

The N2-BET(Barrett-Emmett-Teller) surface area was measured with a quantachrome NOVAWINsystem.

\section{Sorption study:}

5.1. Determination of the sorption capacity: The batch equilibrium technique was employed at room temperature. Different concentrations of metals solutions were prepared in DI water. Typically, a $0.1 \mathrm{gm}$ of HAp/GO nanocomposite was added to $100 \mathrm{~mL}$ of metals solution after a $\mathrm{pH}$ adjustment. The mixture was next shaken at $400 \mathrm{rpm}$ for different durations. The (HAp/GO) sorbent was then filtered by a $0.45 \mu \mathrm{m}$ syringe filter to pass the metals-containing filtrate for Inductively Coupled Plasma - Mass Spectrometry (ICP-MS) Agilent 7700s. The equilibrium sorption capacity (qe, mg/g) of $\mathrm{HAp} / \mathrm{GO}$, which is defined by the equilibrium amount (mg) of metals adsorbed per gram of sorbent was calculated using the general equation:

$\mathrm{qe}=\left(\mathrm{C}_{0}-\mathrm{C}_{\mathrm{t}}\right) \mathrm{V} / \mathrm{M}$

where $C_{o}$ and $C_{t}$ are the metals concentrations $(\mathrm{mg} / \mathrm{l})$ in solution before and after adsorption, $\mathrm{V}$ is the solution volume (L) and $\mathrm{M}$ is the amount ( $\mathrm{g}$ ) of the sorbent employed in the adsorption experiment.

Also the removal efficiency, $\mathrm{R}$, was calculated using the following equation:

$\mathrm{R}=\left(\mathrm{C}_{0}-\mathrm{C}_{\mathrm{t}}\right) / \mathrm{C}_{\mathrm{o}} \times 100$ 
5.2. Kinetics of adsorption: The kinetic progress of sorption processes was monitored by adding $0.1 \mathrm{~g}$ of HAp/GO to $100 \mathrm{~mL}$ metals $(100 \mathrm{mg} / \mathrm{L})$ solution and the mixture was shaken at room temperature for different durations (5-120 min). The same processing of separation and analysis was employed to estimate the sorption capacity ( $\mathrm{qt}, \mathrm{mg} / \mathrm{g}$ ) as a function of contact time $(\mathrm{t}, \mathrm{min})$ to represent the data according to pseudo-first and second-order reaction kinetics (Eq.) (Simonin, 2016) and evaluate qe and the sorption rate constant $(\mathrm{k}, \mathrm{g} / \mathrm{mg} \times \mathrm{min})$.

$\ln (q e-q t)=\ln q e-k_{1} t \quad \quad \mathrm{t} / \mathrm{q}_{\mathrm{t}}=\left(1 / \mathrm{kq}_{\mathrm{e}}{ }^{2}\right)+\left(1 / \mathrm{q}_{\mathrm{e}}\right) \mathrm{t}$

The sorption rate $\mathrm{h}\left(\mathrm{mg} \mathrm{g}^{-1} \mathrm{~min}^{-1}\right)$ was also calculated using the following equation :

$$
\mathrm{H}=\mathrm{kq}_{\mathrm{e}}{ }^{2}
$$

5.3. adsorption isotherm models: adsorption isotherm models of Langmuir and Freundlich were applied to fit the adsorption equilibrium data of $(\mathrm{Cd}$, $\mathrm{Pb}, \mathrm{Cr}, \mathrm{Ni}, \mathrm{Co}$ )metalson HAp/GO composite.

According to the isothermic Langmuir model, adsorption occurs on a sorbent at different homogeneous sites (Chen, 2015) and the linear form can be written as:

$$
C_{e} / q_{e}=1 /\left(K_{L} q_{m}\right)+C_{e} / q_{m}
$$

Where $\mathrm{q}_{\mathrm{e}}$ and $\mathrm{C}_{\mathrm{e}}$ are the amount of equilibrium metal ions on the sorbent $\left(\mathrm{mg} \mathrm{g}^{-1}\right)$ and in the solution $\left(\mathrm{mg} \mathrm{L}^{-1}\right), \mathrm{q}_{\mathrm{m}}$ is the overall monolayer adsorption capability of the sorbent $\left(\mathrm{mg} \mathrm{g}^{-1}\right)$ and $\mathrm{K}_{\mathrm{L}}$ is the constant of Langmuir adsorption $\left(\mathrm{L} \mathrm{mg}^{-1}\right)$. 
Freundlich isotherm model assumes a heterogeneous adsorption surface and different-energy active sites (Chen, 2015) and the Freundlich isotherm model is given in linear form as:

$$
\ln q_{e}=\ln K_{F}+(1 / n) \ln C_{e}
$$

Where $\left(\mathrm{mg} \mathrm{g}^{-1}\right)$ is the Freundlich constant, which is measure of adsorption capacity, and1/nis an empirical parameter related to the nature and strength of the adsorption process and the distribution of the active sites.

Low valuesof $1 / n$ mean that the surface is heterogeneous.

For values in the range $0.1<1 / n<1$, adsorption is favorable . 


\section{RESULTS AND DISCUSSION}

1. Material characterization: FTIR was performed to verify GO and functionalization with HAp nanoparticles (Figure 1), The characteristic absorption bands of GO including alkoxy C-O stretching $\left(1043 \mathrm{~cm}^{-1}\right)$, epoxy $\mathrm{C}-\mathrm{O}$ stretching $\left(1268 \mathrm{~cm}^{-1}\right), \mathrm{O}-\mathrm{H}$ deformation vibrations of tertiary $\mathrm{C}-\mathrm{OH}\left(1406 \mathrm{~cm}^{-1}\right)$, and $\mathrm{C}=\mathrm{O}$ stretching $\left(1700 \mathrm{~cm}^{-1}\right)$, were identified. Also, a strong and broad absorption at $3009 \mathrm{~cm}^{-1}$, due to $\mathrm{O}-\mathrm{H}$ stretching vibrations, and an intense band at $1611 \mathrm{~cm}^{-1}$ corresponding to the $\mathrm{C}=\mathrm{C}$ benzene ring mode was observed (Manoratne et al., 2017). as the spectrum of prepared HAp the bands at 980 and $1023 \mathrm{~cm}^{-1}$ correspond to the PO4 $4^{3-}$ asymmetric stretching; 601 and $564 \mathrm{~cm}^{-1}$ are $\mathrm{PO} 4^{3-}$ antisymmetric deformation. The peaks at 3700 and $630 \mathrm{~cm}^{-1}$ derive from the stretching and librational modes of the $\mathrm{OH}$-ions, respectively (Vuong Hoan et al., 2016). Upon reaction, both spectra of GO / HAp showed substantially reduced bands for oxygen functional GO groups, and some of them totally vanished. In addition, a new absorption band emerged at 1600 $\mathrm{cm}-1$, which could be due to the graphene sheets' $\mathrm{C}=\mathrm{C}$ stretch vibration (Mohandes and Salavati-Niasari, 2014). 

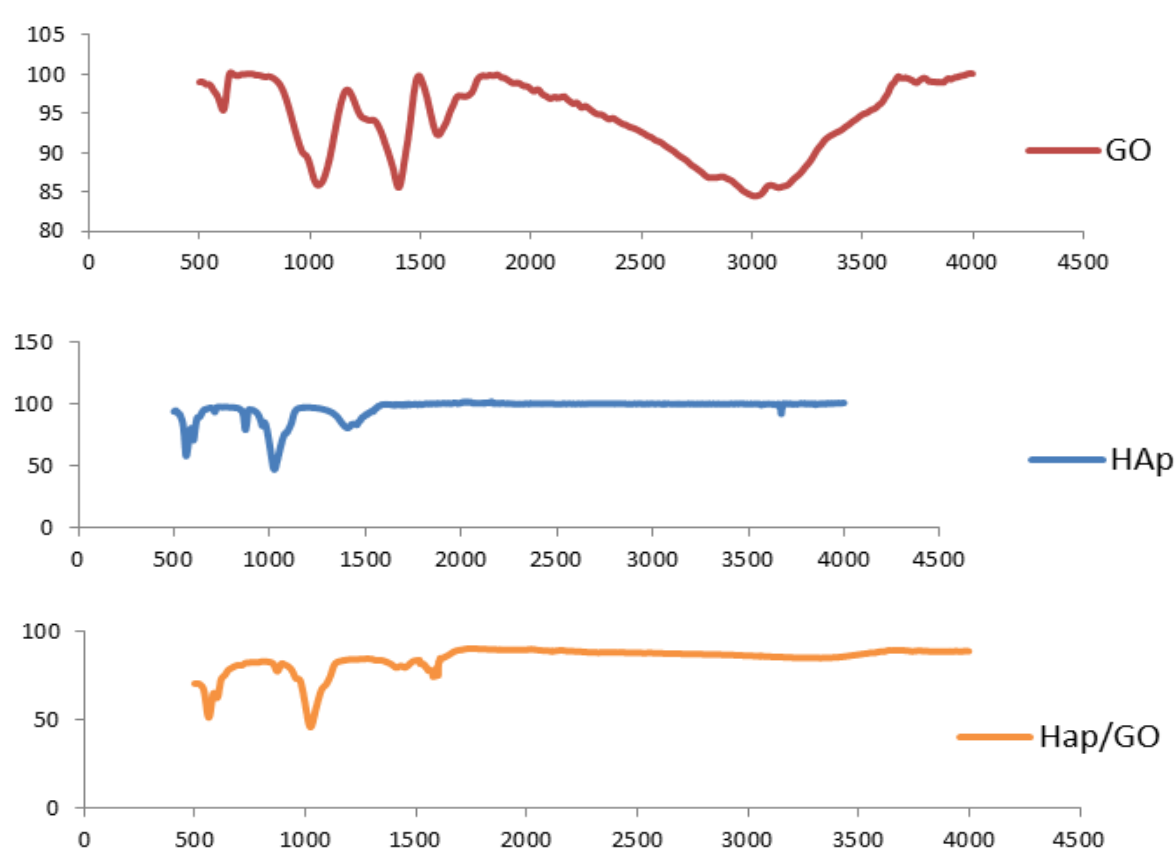

Figure (1): (HAp-GO-HAp/GO) powder FTIR

In the Raman spectra (Figure 2) of HAp/GO the $G$ band was shifted to $1601 \mathrm{~cm}^{-1}$, while the D-band intensity decreased considerably. The G-band shifting may be due to the fact that the chemical interactions between GO's carbon atoms and HAp reactive sites allow the formation of isolated double bonds, resonating at higher frequencies (Ramadas et al., 2017). 


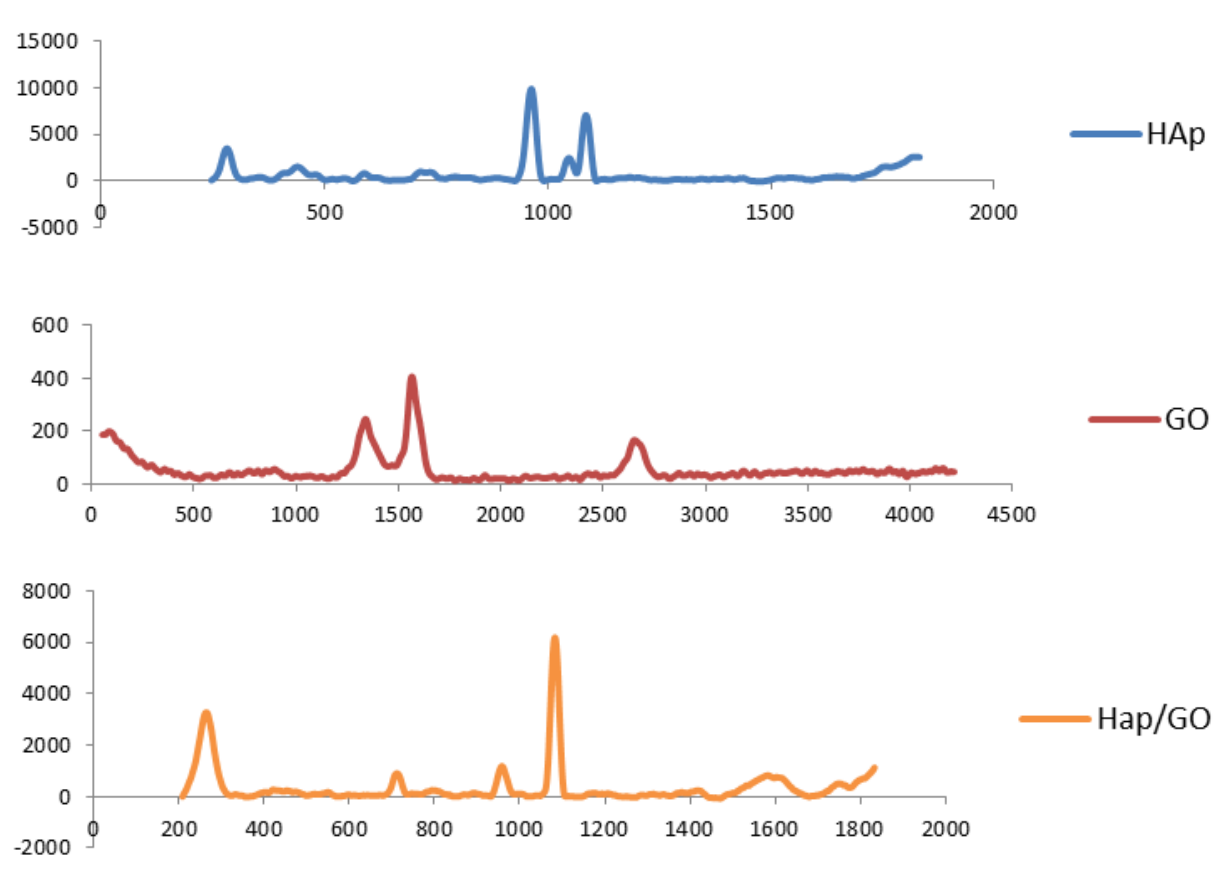

Figure (2): (HAp-GO-HAp/GO) powder RAMAN spectra

(Figure 3) shows the XRD patterns of HA, GO, and GO/HAp. The GO pattern showed the most intense peak at $2 \theta=11.7^{\circ}$ corresponding to the reflection (001). Owing to the presence of functional groups containing oxygen connected on both sides of the graphene sheet; (Stobinski et al., 2014). GO / HAp diffraction patterns reveal characteristic hexagonal phase peaks. Well-defined peaks appeared at $2 \theta$ around $25.9 \circ, 31.9 \circ, 32.9 \circ, 34.1 \circ$ , 39.8॰ 46.7॰ , and 50.5॰, which are attributed, respectively, to the (002), (211), (300), (202), (310), (222), and (321) reflections of HA (Wen et al., 2014). 


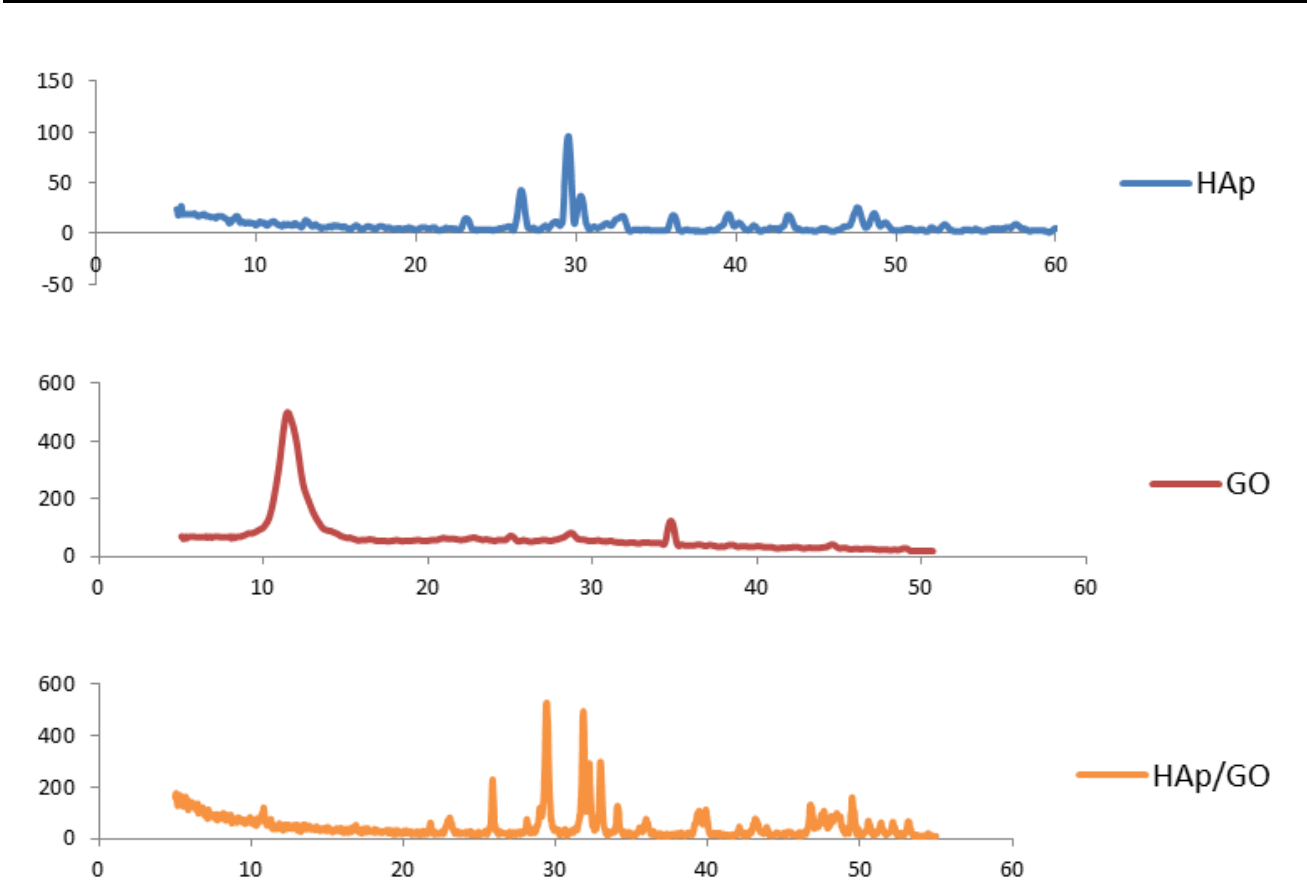

Figure (3): (HAp-GO-HAp/GO) powder XRD patterns

HAp/GO EDX spectrum (Figure 4) showed defined Ca, P, C, and O peaks that can be attributed to the presence of GO and HAp. Furthermore the $\mathrm{Ca} / \mathrm{P}$ atomic ratio of the composite was 3.48 , which is lower than the stoichiometric composition of pure hydroxyapatite. 
Journal of Environmental Sciences (JES)

Institute of Environmental Studies and Research, Ain Shams University

Radwan et al.

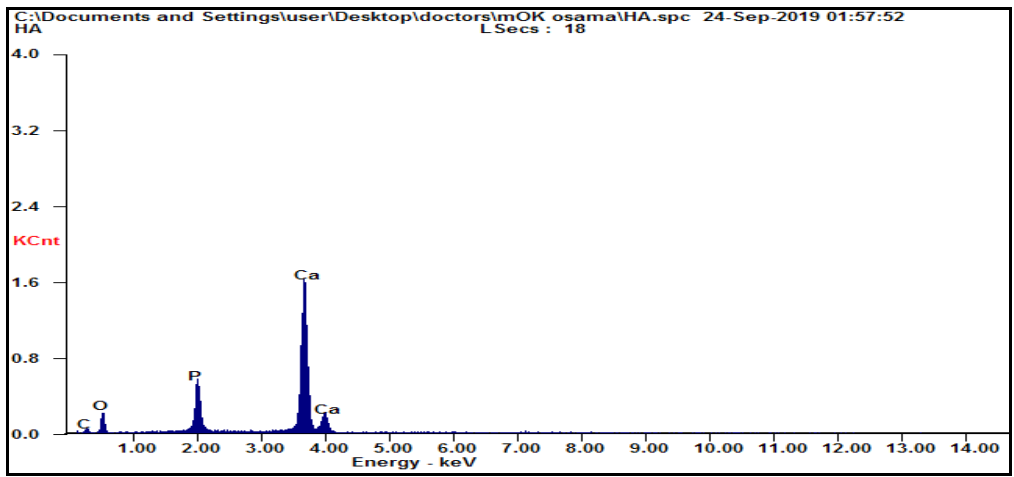

HAp
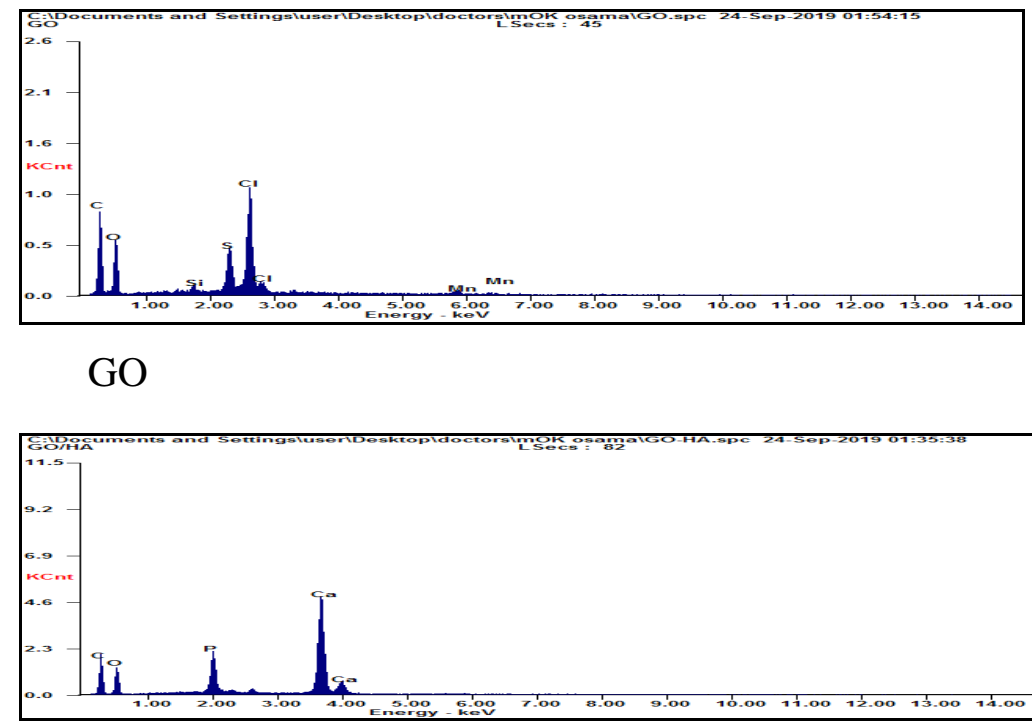

$\mathrm{HAp} / \mathrm{GO}$

Figure (4): (HAp-GO-HAp/GO) powder EDX

According to (Figure 5), (a) shows that large rod like shape HAp can be clearly observed in the TEM micrographs (Ravi et al., 2012). 
Figure (b) show that large and transparent graphene oxide sheets can be clearly observed in the TEM micrographs. The GO sheets show wrinkled and crumbling morphologies which illustrate a flake-like shape (Stobinski et al., 2014).

Figure (c) clearly shows the TEM photos of HAp/GO hybrid products that rod-like HAp nanoparticles are well isolated and randomly dispersed onto the transparent graphene oxide sheets, suggesting a close interaction between graphene and HAp nanoparticles (Ramadas et al., 2017).

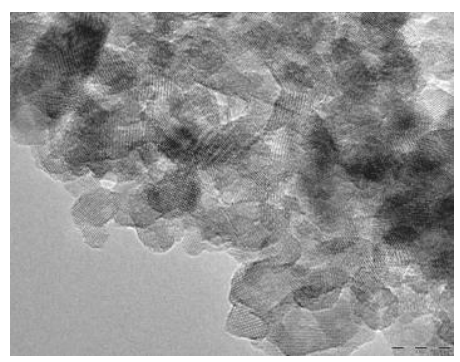

$\mathrm{a}$

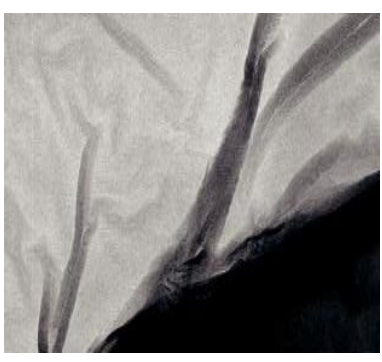

b

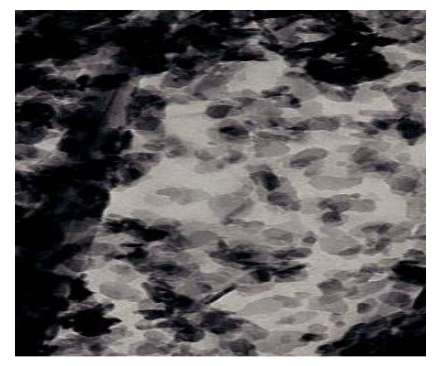

$\mathrm{C}$

Figure (5): (a) HAp, (b) GO, (c) HAp/GO powder TEM

SEM images of GO/HAp, Figures 6 (a), (b) and (c), respectively, Show an entirely different morphology compared to the GO sheets. It can be found in both hybrid materials that HAp nanoparticles are deposited homogeneously onto the graphene sheets. The surface of these nanocomposites shows a rough structure with many granules which means that nHAp covers GO sheets. These results were consistent with TEM results, which showed a homogeneous distribution of HAp nanoparticles on the graphene oxide 
surface suggesting the development of hybrid materials based on graphene (Prongmanee et al., 2019).

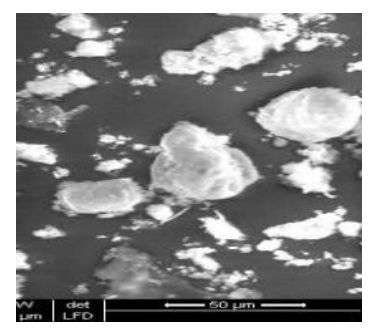

a

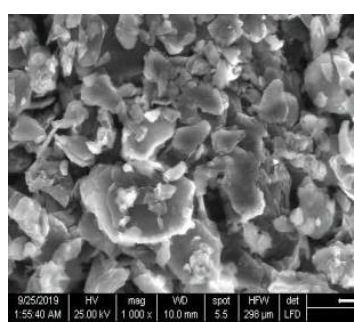

b

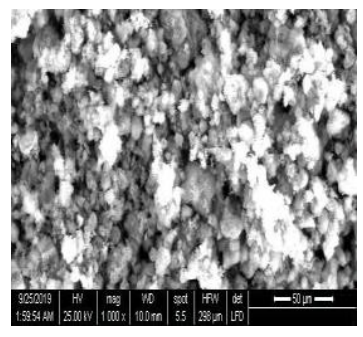

C

Figure (6): (a) HAp, (b) GO, (c) HAp/GO powder SEM

(Figure.7) shows the nitrogen adsorption-desorption isotherm and corresponding Barrett-Joyner-Halenda $(\mathrm{BJH})$ pore size distribution curve for HAp/GO nanocomposite. The SSA observed from the BET was 12.6, 146.8, $75.4 \mathrm{~m}^{2} \mathrm{~g}^{-1}$ for Hap, GO, HAp/GO respectively suggesting that the specific surface area of HAp/GO was largely increased through the graphene incorporated HAp as compared with that of HAp. the BJH desorption cumulative pore volume and average pore size were $0.038 \mathrm{~cm}^{3} \mathrm{~g}^{-1}$ and 12.36 $\mathrm{nm}$, respectively. The higher SSA and mesoporous structure of the asprepared HAp/GO nanocomposite favours the adsorption of heavy metals. The obtained result clearly confirms that the smaller grains of the HAp/GO nanocomposite exhibits higher SSA (Wen et al., 2014). 


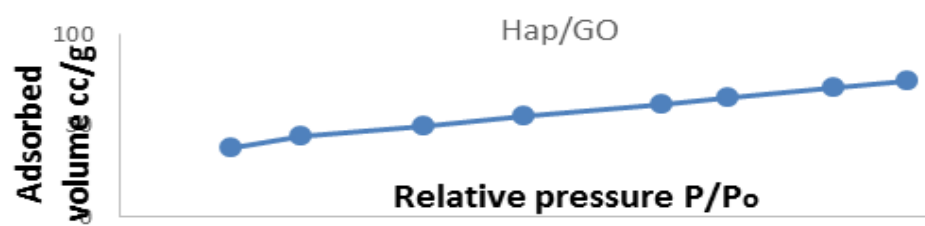

$0.00 E+00 \quad 2.00 E+00 \quad 4.00 E+00 \quad 6.00 E+00 \quad 8.00 E+00 \quad 1.00 E+011.20 E+011.40 E+011.60 E+01$

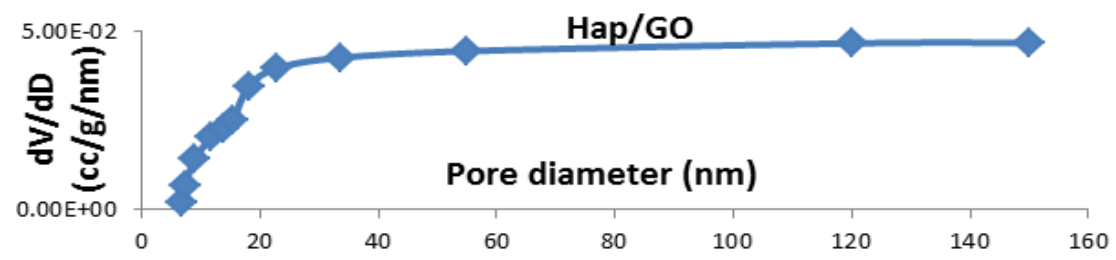

Figure (7): Nitrogen adsorption-desorption isotherm and pore size distribution of the HAp/GO.

\section{Sorption study:}

2.1. Effect of contact time on the adsorption capacity: To show contact time (Figure 8). between the GO/HAp and ( $\mathrm{Cr}, \mathrm{Ni}, \mathrm{Co}, \mathrm{Pb}, \mathrm{Cd})$ metals ion solution, the adsorption capacities of metals ion were measured as a function of time, The plot shows that the effect of $5 \mathrm{mg} / 1$ concentration of the initial metals $(\mathrm{Cr}, \mathrm{Ni}, \mathrm{Co}, \mathrm{Pb}, \mathrm{Cd})$ on the rate of removal at $0.1 \mathrm{~g}$ adsorbent dosage on GO/HAp. It can be seen that with the extension of the contact time the adsorption yield gradually increases and it remained constant after the adsorption equilibrium was established at about $30 \mathrm{~min}$ (Prongmanee et al., 2019). 


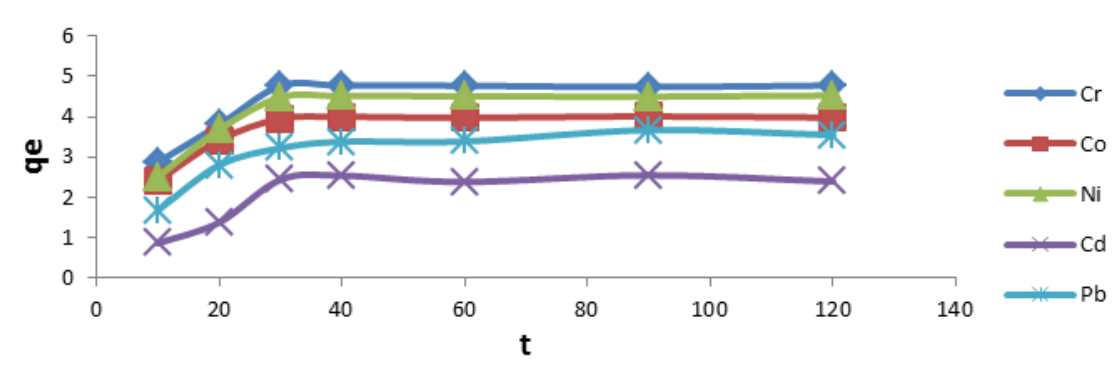

Figure (8): Effect of contact time

\subsection{Effect of initial metals concentration on the adsorbtion capacity:}

(Figure 9) shows the influence of the initial metal concentration on the removal rate at $0.1 \mathrm{~g}$ adsorbent dose $(\mathrm{HAp} / \mathrm{GO})$. It can be seen that in the initial stages the adsorption at various concentrations is rapid and decreases gently with the improvement of adsorption until the equilibrium is reached. As the initial concentration increased, the amount of metals adsorbed at equilibrium (qe) increased. The initial concentration provides a major push to overcome all the metals' mass transfer resistances between the aqueous and solid phases. Hence, the sorption cycle would be improved by higher initial metal concentration. The metals removal efficiency decreased as the metals concentration was increased (Manatunga et al., 2016). 


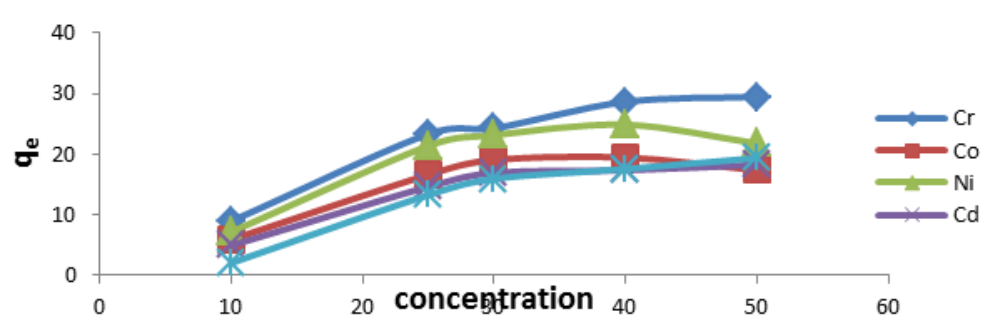

Figure (9): Effect of initial metals concentration.

2.3. Effect of adsorbent dosage on the adsorbtion capacity: The results of experiments to distinguish the effects of adsorbent dosage on $(\mathrm{Cr}, \mathrm{Ni}, \mathrm{Co}, \mathrm{Pb}, \mathrm{Cd})$ metals removal are shown in (Figure 10). and reveal that the removal turnover of $(\mathrm{Cr}, \mathrm{Ni}, \mathrm{Co}, \mathrm{Pb}, \mathrm{Cd})$ metals by the (HAp/GO) nanocomposite increased with an increase in adsorbent dosage. While a prompt increase was observed at adsorbent dosages ranging between 0.05 and0.1 g, a plateau was seen at those ranging between 0.05 and $0.1 \mathrm{~g}$. Increasing of adsorbent dosage above $0.15 \mathrm{~g}$ had meagre effect on the increase in removal efficiency of metals. This may be imputed to the formation of aggregates at higher solid/liquid ratios or to sediment of particles (Moradi and Zare, 2011). 


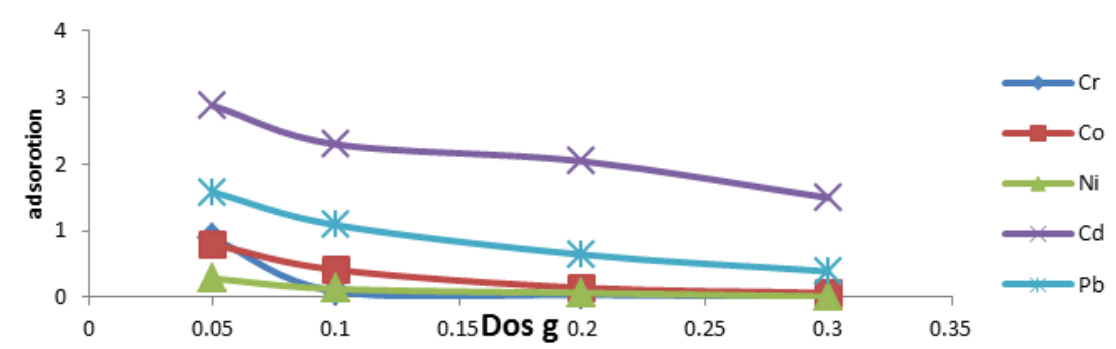

Figure (10): Effect of adsorbent dosage

\subsection{Effect of temperature on the adsorbtion capacity: Temperature is} an essential parameter for the adsorption study, since the temperature of wastewater varies widely. The effect of temperature on the metals uptake capacity of the adsorbent is presented in (Figure 11). The adsorption turnover increased from 25 to $45^{\circ} \mathrm{C}$, indicating the endothermic existence of the metal adsorption reaction on HAp/GO.

The increase in adsorption turnover with increased temperature indicated that metal adsorption by HAp/GO may involve not only physical, but chemical sorption as well. This effect can be attributed to an increase in the number of adsorption sites developed by the rapture of bonds (Manatunga et al., 2016). 
Radwan et al.

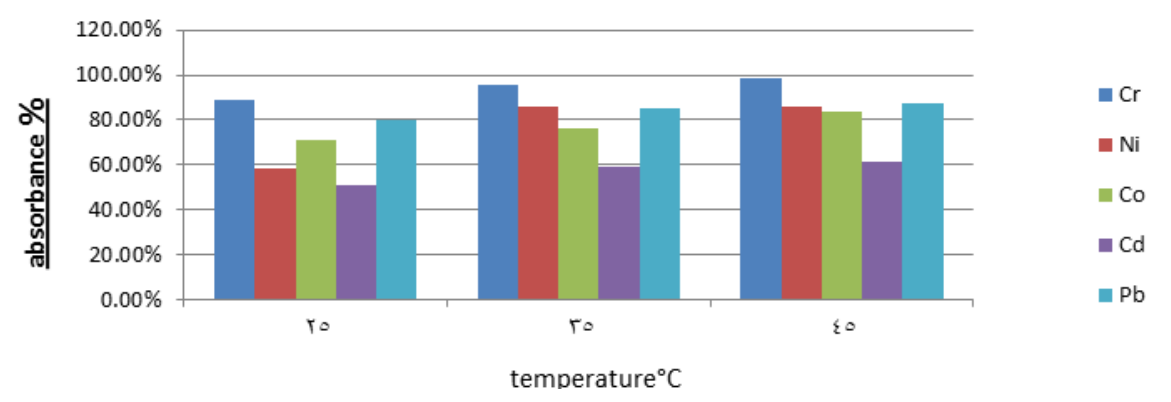

Figure (11): Effect of temperature.

2.5. Effect of $\mathbf{p H}$ on the adsorbtion capacity: The influence of $\mathrm{pH}$ on the sorption process of metals on $\mathrm{HAp} / \mathrm{GO}$ was studied as a function of $\mathrm{pH}$ (Figure 12), changing the $\mathrm{pH}$ is expected to influence the bonding mechanism and the sorption capacity of metals on HAp/GO nanocomposite by changing the electrical surface charge of HAp/GO composite. It might also affect the number of active sites available for this adsorption process.

In this investigation, the metals uptake increased much with $\mathrm{pH}$. This can likely be described in view of a mutual competition between protons $\left(\mathrm{H}^{+}\right)$and the cationic function of metals for the participation on the sorption process on HAp/GO. At low $\mathrm{pH}$, protons are plenty and they could occupy a large number of active adsorption sites of HAp/GO to leave few sites available for metals removal. The accommodation of protons at the HAp/GO composite imparts a cumulative positive charge at the surface which induces an electrostatic repulsion with cationic function of metals, reducing the sorption capacity. On the other hand, at high $\mathrm{pH}$, the proton competition disappears 
and the HAp/GO acquires a negative electrical charge that drives electrostatically the attraction with positively charged metals to increase the removal efficiency (Wen et al., 2014).

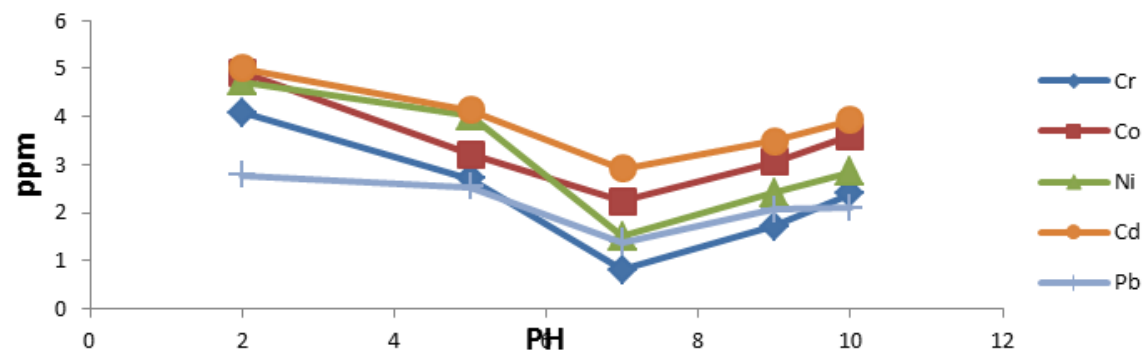

Figure (12): Effect of $\mathrm{pH}$

2.6. Kinetics of adsorption: The kinetic models pseudo first order and pseudo second order were used to investigate the kinetics of metal adsorption on the composite HAp/GO (figures 13,14).

The pseudo-first - order model might be expressed in linear form as (Simonin, 2016): $\ln (q e-q t)=\ln q e-k_{1} t$

Where, $q e$ and $q t$ are the amounts of metal ion adsorbed on adsorbent $\left(\mathrm{mg} \cdot \mathrm{g}^{-1}\right)$ at equilibrium and at time $t$, respectively, and $k^{1}$ is the rate constant of first order adsorption $\left(\mathrm{min}^{-1}\right)$.

Straight line plots of $\ln (q e-q t)$ against $t$ were used to determine the rate constant, $k 1$.

The pseudo second order model in a linear form may be expressed as (Simonin, 2016): $t q t=1\left(k_{2} q e_{2}\right)+t q e$ 
Where, $k^{2}$ is the rate constant of second-order adsorption $\left(\mathrm{g} \mathrm{mg}^{-1} \mathrm{~min}^{-1}\right)$. Straight-line plots of $t / q t$ against $t$ were tested to obtain rate parameters.

A comparison of pseudo-first order and pseudo second order kinetic models of metal adsorption onto $\mathrm{HAp} / \mathrm{GO}$ at various time is illustrated in Table (1). The results show that the coefficients of determination $\left(R^{2}\right)$ for pseudo second order model are higher compared with those of pseudo first order one.

These results suggest that the kinetics of $(\mathrm{Cr}, \mathrm{Ni}, \mathrm{Co}, \mathrm{Pb}, \mathrm{Cd})$ adsorption on the HAp/GO follow the pseudo second-order model table 1.

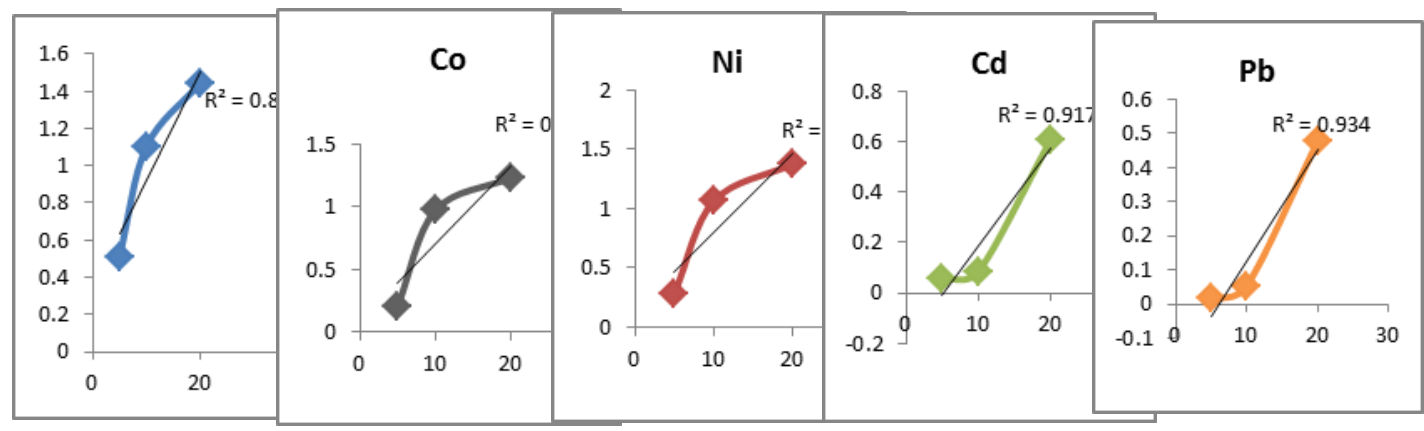

Figure (13): Pseudo frist order model 


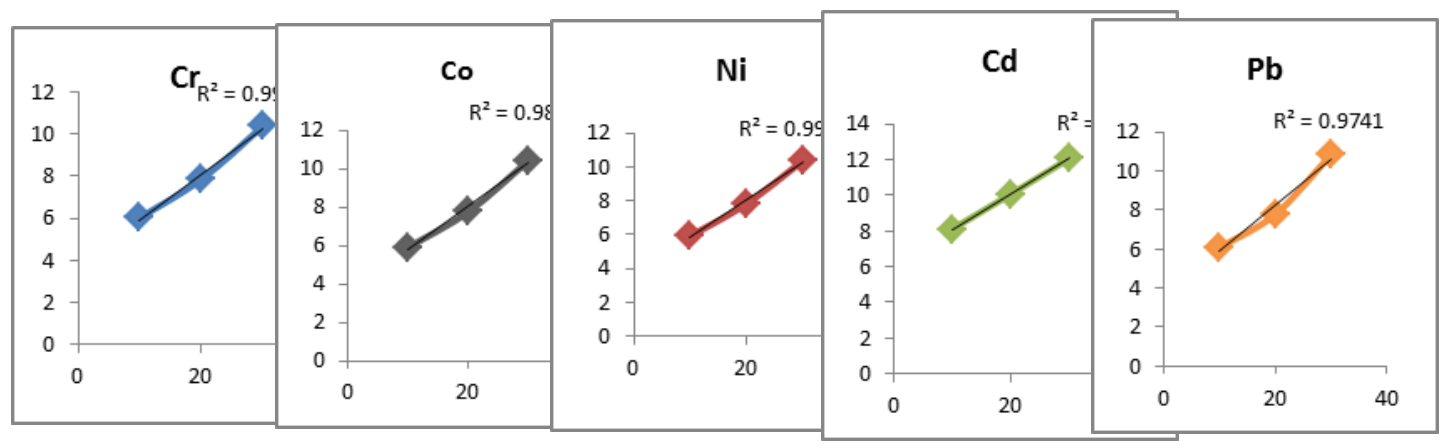

Figure (14): Pseudo second order model.

Table (1): Results of Kinetics of adsorption of GO/Hap powder

\begin{tabular}{|c|c|c|}
\hline \multirow{2}{*}{} & pseudo-first-order & pseudo-second order \\
\cline { 2 - 3 } & $\mathbf{R}^{\mathbf{2}}$ & $\mathbf{R}^{\mathbf{2}}$ \\
\hline $\mathrm{Cr}$ & 0.886 & 0.991 \\
\hline $\mathrm{Co}$ & 0.797 & 0.989 \\
\hline $\mathrm{Ni}$ & 0.824 & 0.992 \\
\hline $\mathrm{Cd}$ & 0.917 & 0.999 \\
\hline $\mathrm{Pb}$ & 0.934 & 0.997 \\
\hline
\end{tabular}

2.7. Adsorption isotherm models: The Langmuir and Freundlich isotherm adsorption models were applied to match the HAp/GO composite adsorption equilibrium data of $(\mathrm{Cr}, \mathrm{Ni}, \mathrm{Co}, \mathrm{Pb}, \mathrm{Cd})$ (figures 15,16) .

According to the isothermic Langmuir model, adsorption takes place on a sorbent at specific homogeneous sites and the linear form can be written as (Matouq et al., 2015): Cel qe $=1 /\left(K_{L} q_{m}\right)+C e$

Where, qe and $\mathrm{Ce}$ are the equilibrium metal ion contents on the sorbent $\left(\mathrm{mg} \mathrm{g}^{-1}\right)$ and in the solution $\left(\mathrm{mg} \mathrm{L}^{-1}\right)$, respectively, $q_{m}$ is the maximum 
monolayer adsorption capacity of the sorbent $\left(\mathrm{mg} \mathrm{g}^{-1}\right)$, and $K_{L}$ is the Langmuir adsorption constant $\left(\mathrm{L} \mathrm{mg}^{-1}\right)$.

Freundlich isotherm model assumes a heterogeneous adsorption surface and different energy active sites and the Freundlich isotherm model is given in linear form (Matouq et al., 2015): $\ln q e=\ln K_{F}+(1 / n) \ln C e$

where $K_{F}\left(\mathrm{mg} \mathrm{g}^{-1}\right)$ is the Freundlich constant, which is a measure of adsorption capacity, and $1 / n$ is an empirical parameter related to the nature and strength of the adsorption process and the distribution of the active sites.

Low values of $1 / n$ mean that the surface is heterogeneous. For values in the range $0.1<1 / n<1$, adsorption is favourable (Dada et al., 2012).

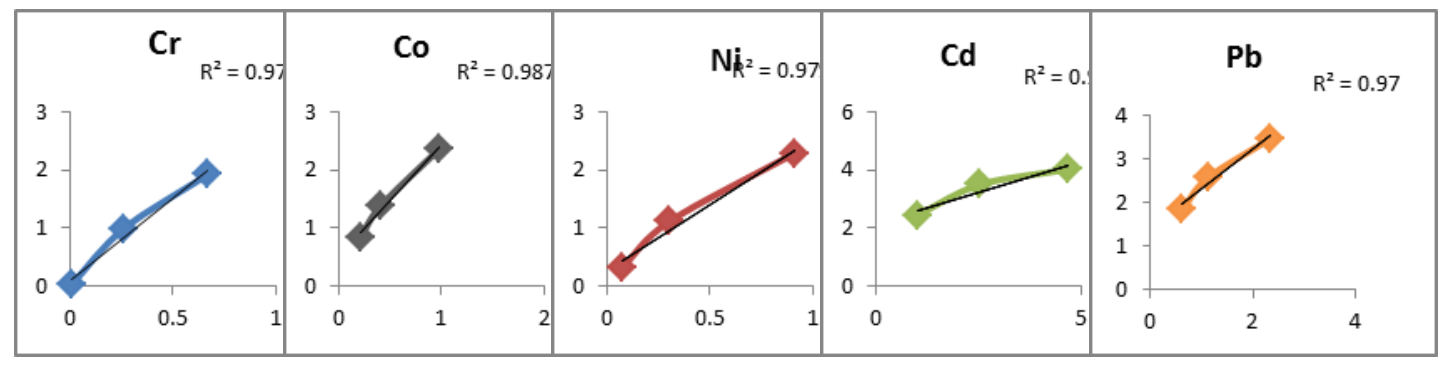

Figure (15): Langmuir isotherm 


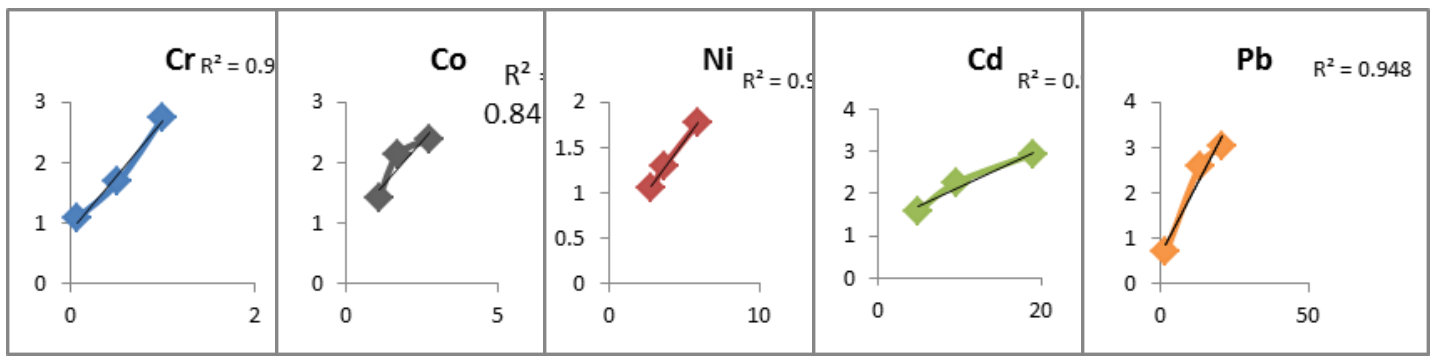

Figure (16): Freundlich isotherm

The Langmuir and Freundlich isotherm parameters for metal ion adsorption onto the HAp/GO were calculated by plotting of $q e$ versus $C e$ and the results are presented in Table 2 .

The equilibrium data of metal ion adsorption on to the HAp/GO can be well fitted by the two adsorption isotherm models since the coefficients of determination $\left(R^{2}\right)$ in the two models are very close. The high correlation to both Langmuir and Freundlich isotherms implies amono layer adsorption and the existence of heterogeneous surface in the adsorbents, respectively (Vuong Hoan et al., 2016).

Table (2): Adsorption isotherm models of GO/Hap powder

\begin{tabular}{|c|c|c|}
\hline \multirow{2}{*}{} & Langmuir & Freundlich \\
\cline { 2 - 3 } & $\mathbf{R}^{\mathbf{2}}$ & $\mathbf{R}^{\mathbf{2}}$ \\
\hline $\mathrm{Cr}$ & 0.979 & 0.983 \\
\hline $\mathrm{Co}$ & 0.987 & 0.942 \\
\hline $\mathrm{Ni}$ & 0.979 & 0.992 \\
\hline $\mathrm{Cd}$ & 0.918 & 0.966 \\
\hline $\mathrm{Pb}$ & 0.979 & 0.948 \\
\hline
\end{tabular}




\section{CONCLUSION}

This research illustrates the success of hydroxyapatite/graphene (HAp/GO) composite nanocomposite in the removal of metals $(\mathrm{Cr}, \mathrm{Ni}, \mathrm{Co}, \mathrm{Pb}, \mathrm{Cd})$ from aqueous solutions in wastewater treatment. The mechanism of adsorption was investigated as a function of contact time, initial concentration of metals, $\mathrm{pH}$ and dosing of sorbents. The kinetics of the sorption process could be fitted to a pseudo-second-order reaction model. The Langmuir and Freundlich isotherm adsorption models were applied to match the HAp/GO composite adsorption equilibrium data of ( $\mathrm{Cr}, \mathrm{Ni}, \mathrm{Co}, \mathrm{Pb}, \mathrm{Cd})$, The maximum adsorption amounts of metals over HAp/GO calculated are (4.77) $\mathrm{mg} / \mathrm{g}$ for $\mathrm{Cr},(3.99) \mathrm{mg} / \mathrm{g}$ for Co , (4.51) $\mathrm{mg} / \mathrm{g}$ for $\mathrm{Ni}$, (2.53) mg/g for $\mathrm{Cd}$ and (3.78) $\mathrm{mg} / \mathrm{g}$ for $\mathrm{Pb}$, rather higher than the otherreports. This result demonstrates that the obtained HAp/GO nanocomposite is a potential adsorbent for treating water sources contaminated by heavy metals.

\section{REFERENCES}

Ali, H.; Khan, K. \& Ilahi, I. (2019): Environmental chemistry and ecotoxicology of hazardous heavy metals: environmental persistence, toxicity, and bioaccumulation. journal of chemistry.

chang, h. \& wu, h. (2013): graphene-based nanocomposites: preparation, functionalization, and energy and environmental applications. energy \& environmental science, 6, 3483-3507.

chen, x. (2015): modeling of experimental adsorption isotherm data. information, 6, 14-22. 
chung, z. 1., tan, y. h., san chan, y., kansedo, j., mubarak, n., ghasemi, m. \& abdullah, m. o. (2019): life cycle assessment of waste cooking oil for biodiesel production using waste chicken eggshell derived cao as catalyst via transesterification. biocatalysis and agricultural biotechnology, 21, 101317.

dada, a., olalekan, a., olatunya, a. \& dada, o. (2012): langmuir, freundlich, temkin and dubinin-radushkevich isotherms studies of equilibrium sorption of $\mathrm{zn} 2+$ unto phosphoric acid modified rice husk. iosr journal of applied chemistry, 3, 38-45.

guerrero-contreras, j. \& caballero-briones, f. (2015): graphene oxide powders with different oxidation degree, prepared by synthesis variations of the hummers method. materials chemistry and physics, 153, 209-220.

hassan, m. a., mohammad, a. m., salaheldin, t. a. \& el-anadouli, b. e. (2018): a promising hydroxyapatite/graphene hybrid nanocomposite for methylene blue dye's removal in wastewater treatment. international journal of electrochemical science, 13, 8222-8240.

hincke, m. t., nys, y., gautron, j., mann, k., rodriguez-navarro, a. b. \& mckee, m. d. (2012): the eggshell: structure, composition and mineralization. front biosci, 17, 80 .

hui, p., meena, s., singh, g., agarawal, r. \& prakash, s. (2010): synthesis of hydroxyapatite bio-ceramic powder by hydrothermal method. journal of minerals \& materials characterization \& engineering, 9 , 683-692.

laca, a., laca, a. \& díaz, m. (2017): eggshell waste as catalyst: a review. journal of environmental management, 197, 351-359.

lee, s. s., lim, j. e., abd el-azeem, s. a., choi, b., oh, s.-e., moon, d. h. \& ok, y. s. (2013): heavy metal immobilization in soil near abandoned mines using eggshell waste and rapeseed residue. environmental science and pollution research, 20, 1719-1726. 
manatunga, d. c., de silva, r. m., de silva, k. n. \& ratnaweera, r. (2016): natural polysaccharides leading to super adsorbent hydroxyapatite nanoparticles for the removal of heavy metals and dyes from aqueous solutions. rsc advances, 6, 105618-105630.

manoratne, c., rosa, s. \& kottegoda, i. (2017): xrd-hta, uv visible, ftir and sem interpretation of reduced graphene oxide synthesized from high purity vein graphite. material science research india, 14, 19-30.

matouq, m., jildeh, n., qtaishat, m., hindiyeh, m. \& al syouf, m. q. (2015): the adsorption kinetics and modeling for heavy metals removal from wastewater by moringa pods. journal of environmental chemical engineering, 3, 775-784.

mohandes, f. \& salavati-niasari, m. (2014): freeze-drying synthesis, characterization and in vitro bioactivity of chitosan/graphene oxide/hydroxyapatite nanocomposite. rsc advances, 4, 2599326001.

moradi, o. \& zare, k. (2011): adsorption study of the lysozyme from aqueous solution onto hydroxyapatite nanopowders. journal of physical \& theoretical chemistry, 7, 55-63.

prongmanee, w., alam, i. \& asanithi, p. (2019): hydroxyapatite/graphene oxide composite for electrochemical detection of 1-tryptophan. journal of the taiwan institute of chemical engineers, 102, 415423.

rahmani-sani, a., singh, p., raizada, p., lima, e. c., anastopoulos, i., giannakoudakis, d. a., sivamani, s., dontsova, t. a. \& hosseinibandegharaei, a. (2020): use of chicken feather and eggshell to synthesize a novel magnetized activated carbon for sorption of heavy metal ions. bioresource technology, 297, 122452. 
ramadas, m., bharath, g., ponpandian, n. \& ballamurugan, a. (2017): investigation on biophysical properties of hydroxyapatite/graphene oxide (hap/go) based binary nanocomposite for biomedical applications. materials chemistry and physics, 199, 179-184.

ravi, n. d., balu, r. \& sampath kumar, t. (2012): strontium-substituted calcium deficient hydroxyapatite nanoparticles: synthesis, characterization, and antibacterial properties. journal of the american ceramic society, 95, 2700-2708.

simonin, j.-p. (2016): on the comparison of pseudo-first order and pseudosecond order rate laws in the modeling of adsorption kinetics. chemical engineering journal, 300, 254-263.

stobinski, 1., lesiak, b., malolepszy, a., mazurkiewicz, m., mierzwa, b., zemek, j., jiricek, p. \& bieloshapka, i. (2014): graphene oxide and reduced graphene oxide studied by the xrd, tem and electron spectroscopy methods. journal of electron spectroscopy and related phenomena, $195,145-154$.

vilela, d., parmar, j., zeng, y., zhao, y. \& sánchez, s. (2016): graphene-based microbots for toxic heavy metal removal and recovery from water. nano letters, 16, 2860-2866.

vuong hoan, n. t., anh thu, n. t., duc, h. v., cuong, n. d., quang khieu, d. \& vo, v. (2016): fe3o4/reduced graphene oxide nanocomposite: synthesis and its application for toxic metal ion removal. journal of chemistry, 2016.

wen, t., wu, x., liu, m., xing, z., wang, x. \& xu, a.-w. (2014): efficient capture of strontium from aqueous solutions using graphene oxidehydroxyapatite nanocomposites. dalton transactions, 43, 74647472 .

zaaba, n., foo, k., hashim, u., tan, s., liu, w.-w. \& voon, c. (2017): synthesis of graphene oxide using modified hummers method: solvent influence. procedia engineering, 184, 469-477. 


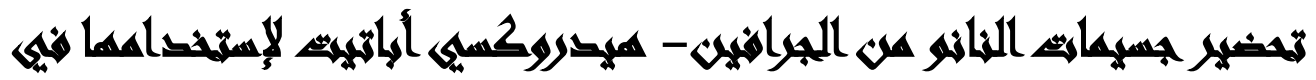

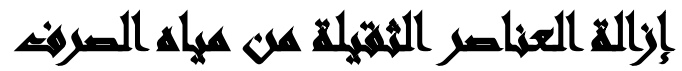

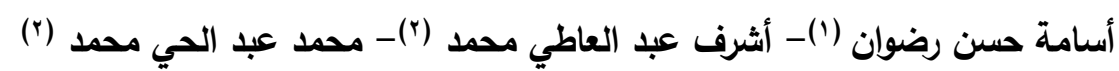

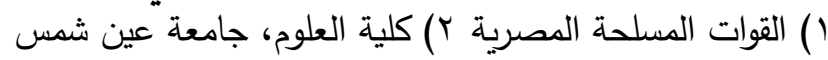

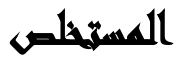

فى هذا البحث، تم إستخدام وإعادة تدوير المخلفات البيولوجية مثال (قثر البيض) محل الدراسة

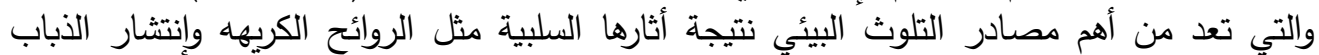

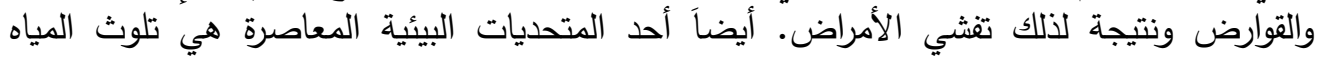

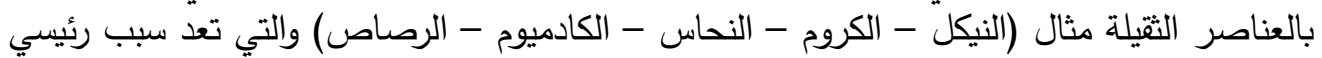

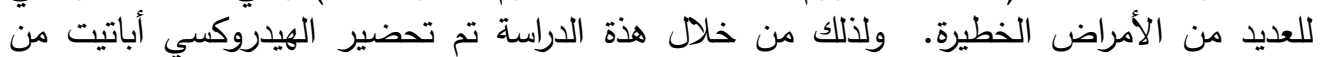

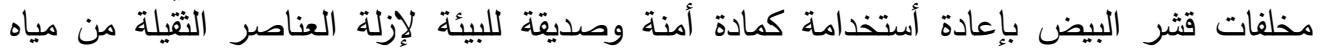

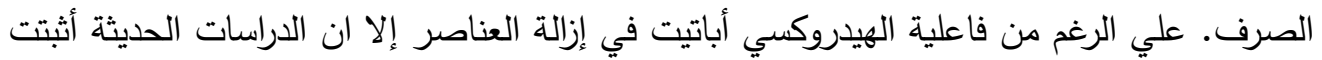

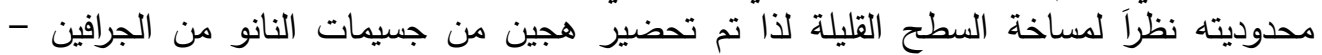

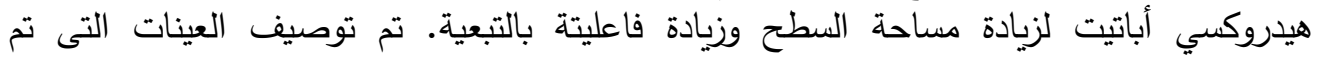

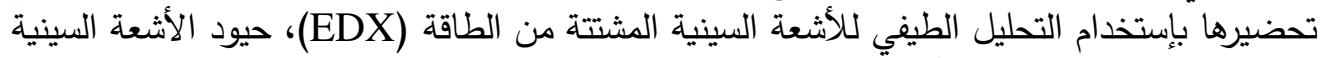

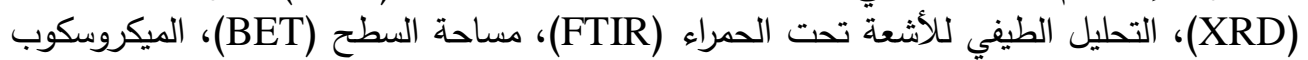

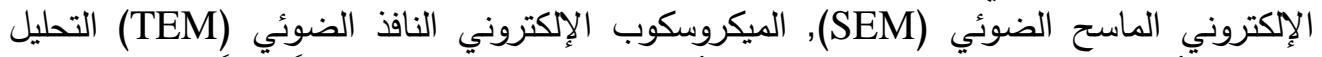

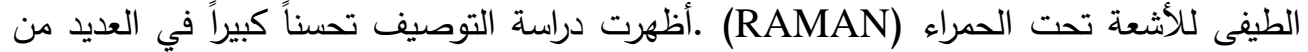

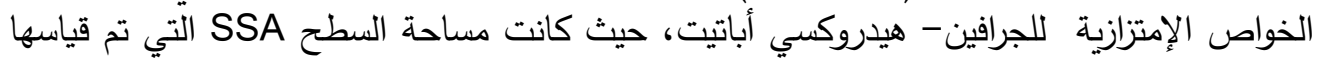

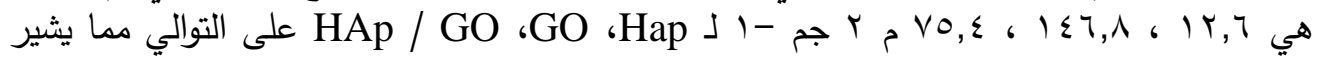

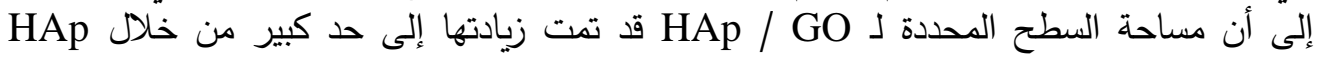

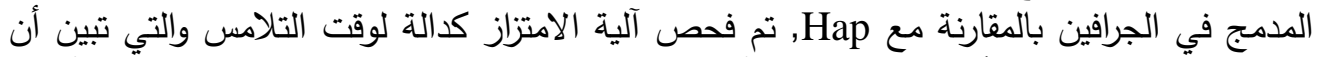

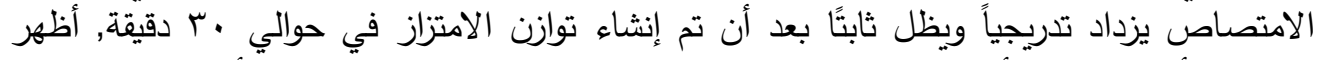

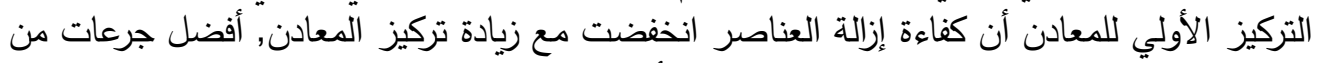

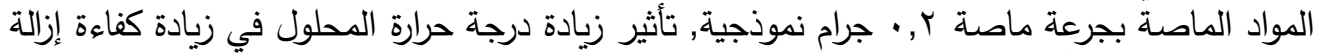

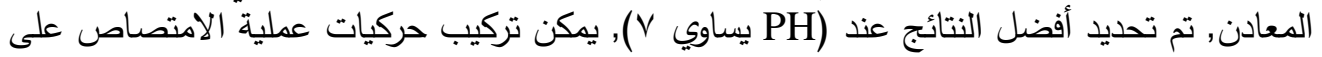
نموذج تفاعل من الدرجة الثانية الزائفة. 


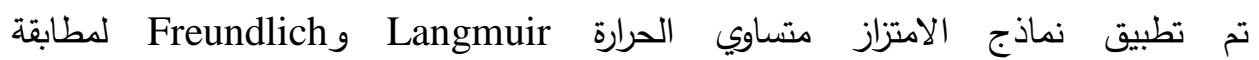

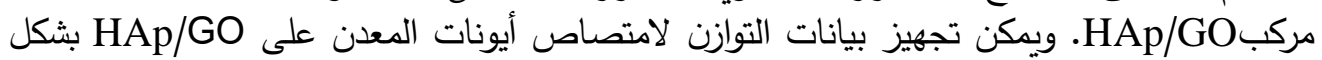

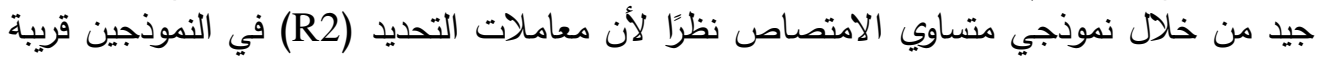

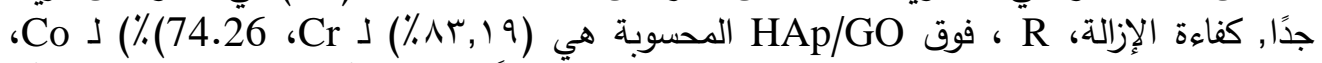

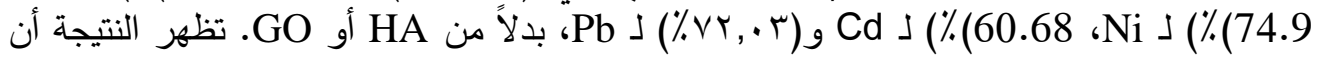
مركب النانو HAp/GO الذي تم الحصول عليه هو مادة ماصة نموذجية لمعالجة المياه الملوثة بالعناصر الثثيلة. الكلمات الدالة: الإمتزاز ، المعادن الثقيلة، الهيدروكسى أباتيت أكسيد الجرافين. 